\title{
Factors affecting estrus and ovulation time in weaned sows with induced ovulation by GnRH administration in different seasons
}

\author{
Pachara PEARODWONG ${ }^{1,4)}$, Chanyuth TRETIPSKUL ${ }^{2)}$, Nicoline M. SOEDE ${ }^{3)}$ and \\ Padet TUMMARUK ${ }^{1,4) *}$ \\ ${ }^{1)}$ Department of Obstetrics, Gynaecology, and Reproduction, Faculty of Veterinary Science, \\ Chulalongkorn University, Bangkok 10330, Thailand \\ 2)Department of Technology of Farm Management, Faculty of Agro-Industry, Panyapiwat Institute of \\ Management, Nonthaburi 11120, Thailand \\ ${ }^{3)}$ Adaptation Physiology, Department of Animal Sciences, Wageningen University, Wageningen 6700AH, \\ The Netherlands \\ ${ }^{4)}$ Swine Reproduction Research Unit, Chulalongkorn University, Bangkok, 10330, Thailand
}

\section{J. Vet. Med. Sci.}

81(11): 1567-1574, 2019

doi: 10.1292/jvms.18-0429

Received: 6 December 2018 Accepted: 22 August 2019 Advanced Epub:

13 September 2019

\begin{abstract}
Follicle development in post-weaning sows is influenced by various factors. To control ovulation time using hormone, factors that influence ovulation should be investigated. The present study was performed to evaluate the effect of GnRH (buserelin) administration in relation to season and sow parameters on ovulation time in weaned sows. Seventy-seven weaned sows were divided into the following groups: control (hot season, $n=21$; cool season, $n=16$ ) and treatment (hot season, $\mathrm{n}=22$; cool season, $\mathrm{n}=18$ ). Sows were kept in a close house equipped with an evaporative cooling system. Ovulation time was determined every $6 \mathrm{hr}$ using transrectal ultrasonography. Administration of $10 \mu \mathrm{g}$ buserelin at $72 \mathrm{hr}$ after weaning affected estrus-toovulation interval (EOI) and weaning-to-ovulation interval (WOI) in sows $(P<0.05)$. The percentage of sows that ovulated between $44-56 \mathrm{hr}$ after injection was higher in the cool season than in hot season $(P<0.05)$. Weaning-to-estrus interval (WEI) and injection-to-estrus interval (IEI) were affected by season $(P<0.05)$. Body condition score $(B C S)$ of sows influenced EOI $(P<0.01)$. Sows with low backfat thickness, lactation length $<20$ days, or litter weight $\geq 67 \mathrm{~kg}$, had delayed injection-toovulation interval $(P<0.05)$. In conclusions, buserelin administration $(10 \mu \mathrm{g}$, at $72 \mathrm{hr}$ after weaning) advanced ovulation. Hot season prolonged ovulation time. Sows that were weaned with lactation length of at least 20 days, litter weight less than $67 \mathrm{~kg}$, or BCS of at least 3, had better responses to buserelin injection. High backfat reserve after weaning is important for ovulation induction response by buserelin injection.
\end{abstract}

KEY WORDS: buserelin, ovulation induction, season, sow

To optimize the efficiency of artificial insemination (AI) in pigs, the timing of ovulation after weaning should be controlled. Because of this, ovulation induction protocols have been developed [10]. Earlier protocols induced both follicle development and ovulation time (e.g. using eCG after weaning and hCG 72-84 hr later) [5], but lately, protocols that use only GnRH [1, 10, 12] or LH agonist have been developed $[6,31]$. These products are administered at a fixed time from weaning [1, 6] or from estrus [12, 31]. Such protocols using GnRH agonist have been found to be successful in minimizing weaning-to-ovulation interval (WOI) or estrus-to-ovulation interval (EOI) $[1,22,35]$. However, the variation in response after GnRH agonist administration among animals i.e., interval from GnRH administration to onset of ovulation, or to the end of ovulation can be quite large [5]. The variations in results can be due to factors related to induction protocols, such as dosage used, type of analogue, and timing of administration in relation to follicle development [17]. In nature, post-weaning, follicle development is influenced by various factors, such as season, parity $[2,32]$, lactation weight loss [28, 32], lactation length (LL) [16], backfat thickness (BF), and litter weight at weaning (LW) [13]. These factors may affect the onset of estrus and ovulation time after GnRH treatment. Thus, to achieve control over ovulation time using hormonal stimulation, factors influencing ovulation should be investigated. The objectives of the present study were to evaluate the effects of season on estrus onset and ovulation time in GnRH agonist (buserelin) treated and non-buserelin treated sows, in a tropical climate, and to evaluate the effects of some sow factors, including parity, body condition, LL, and LW at weaning on estrus and ovulation time. 


\section{MATERIALS AND METHODS}

\section{Animal care, housing, and management}

The experimental procedures were performed according to the Ethical Principles and Guidelines for the Use of Animals, National Research Council of Thailand. The experimental procedure was approved and licensed by the Chulalongkorn University animal care and use committee (protocol number 1731012). The study was conducted on a commercial Landrace $\mathrm{x}$ Yorkshire crossbred swine herd containing 2,500 sows, with a weekly weaning system, in the southern part of Thailand during April (hot season) and December (cool season). During lactation, sows and their piglets were housed in individual farrowing pens. Piglet cross-fostering was performed within 4 days after farrowing, to standardize piglet numbers (10-12 piglets) considering the size of piglet and the number of sow teats available. The lactating sows were fed twice per day (total about 5-6 kg) a diet containing 3.2 Mcal energy $/ \mathrm{kg}$ and $18.0 \%$ crude protein. On average, $10.6 \pm 0.8$ piglets with a litter weight of $66.6 \pm 5.7 \mathrm{~kg}$ were weaned after lactation length of $20.1 \pm 2.3$ days. The weaned sows (parity numbers $1-5)$ were moved to the mating house, where they were kept in stalls equipped with an evaporative cooling system with a concrete slatted floor, and provided with $2.5 \mathrm{~kg}$ of feed per day (3.0 Mcal energy $/ \mathrm{kg}$ and $15.0 \%$ crude protein). Water was provided on demand via a drinking nipple. Temperature and relative humidity inside the barn were measured using digital thermo-hygrometer (Micro and Sensor Application Co., Bangkok, Thailand). The device was placed at $1.5 \mathrm{~m}$ above the floor in the center of the barn. The records included daily minimum and maximum as well as current actual temperatures and humidity. Current actual temperature and humidity were recorded at 0100, 0700, 1300, and 1900 hr. The average temperature and humidity in hot and cool seasons were calculated and they are presented in Table 1.

\section{Experimental design}

To find a suitable time for GnRH agonist injection, the effects of timing of buserelin injection (72 vs. $84 \mathrm{hr}$ after weaning) were first evaluated. A pilot study was conducted on 24 weaned sows (parity numbers $2.6 \pm 1.0$, mean $\pm \mathrm{SD}$ ). The sows were divided into 3 groups: control $(n=8$; parity numbers $2.5 \pm 1.0$, mean $\pm \mathrm{SD})$, treatment72 $(\mathrm{n}=8$; parity numbers $2.7 \pm 0.9$, mean $\pm \mathrm{SD})$, and treatment $84(\mathrm{n}=8$; parity numbers $2.5 \pm 1.3$, mean $\pm \mathrm{SD})$. The control sows did not receive the hormone, whereas treatment72 and treatment84 sows received intramuscular injections of $10 \mu \mathrm{g}(2.5 \mathrm{~m} l)$ buserelin (Receptal ${ }^{\circledR}$, Merck Animal Health, Madison, NJ, U.S.A.) at 72 and $84 \mathrm{hr}$ after weaning, respectively, to induce ovulation.

To induce ovulation in weaned sows, previous studies recommended treatment with GnRH between $83-89 \mathrm{hr}$ after weaning [1, $5,10]$. However, weaning-to-estrus interval (WEI) can vary among herds [30]. In the present study, WEI of the sows was quite short (averaged $3.9 \pm 0.2$ days); hence the onset of GnRH injection must be carefully selected. In the pilot study, the administration of GnRH at either 72 or $84 \mathrm{hr}$ after weaning could effectively induce ovulation. Therefore, in the main experiment, the timing of $\mathrm{GnRH}$ injection at $72 \mathrm{hr}$ after weaning was chosen to obtain the major population of weaned sows that mostly exhibited standing estrus between 3-4 days post-weaning.

In the main experiment, GnRH injections were used to induce ovulation in weaned sow. Seventy-seven weaned sows were divided into the following groups: control (hot season, $n=21$; cool season, $n=16$ ) and treatment (hot season, $n=22$; cool season, $\mathrm{n}=18)$. Treatment sows received an intramuscular injection of $10 \mu \mathrm{g}(2.5 \mathrm{ml})$ buserelin at $72 \mathrm{hr}$ after weaning to induce ovulation, while the control sows did not receive hormone. In the control group, sows were inseminated twice at 12 and $36 \mathrm{hr}$ after the onset of estrus. In the treatment group, sows were inseminated at $32 \mathrm{hr}$ after buserelin administration. Reproductive performance data including farrowing rate, total number of piglets born per litter, number of piglets born alive per litter, number of stillborn piglets per litter, number of mummified fetuses per litter, piglet body weight at birth, number of piglets at weaning, and piglets' body weight at weaning were compared between control and treatment groups.

\section{Sow body condition score and backfat thickness}

On the day of weaning, body condition score (BCS) and BF were assessed. The BCS of the sows was based on a previous reported scoring system [21] that combines visual assessment and palpation of the body. The BCS varied from 1-5: score 1 (emaciated), score 2 (thin), score 3 (ideal), score 4 (fat), score 5 (overly fat). Body condition was scored by the same person. BF thickness was determined using A-mode ultrasonography (Renco Lean-meater ${ }^{\circledR}$, Renco Corporation, Golden Valley, MN, U.S.A.) at the level of P2 position (6-8 cm length from body midline at the level of the last rib) on both sides. The average of the left and right measurements is a representative of $\mathrm{BF}$. On average, $\mathrm{BF}$ (mean $\pm \mathrm{SD}$ ) of weaned sows was $15.4 \pm 3.2 \mathrm{~mm}(\mathrm{range} 10-23 \mathrm{~mm}$ ).

Table 1. Temperature and relative humidity in cool and hot seasons (means \pm SD)

\begin{tabular}{lccc}
\hline \multicolumn{1}{c}{ Variables } & Cool & Hot & $P$ value \\
\hline Average temperature $\left({ }^{\circ} \mathrm{C}\right)$ & $26.2 \pm 0.2$ & $28.0 \pm 0.6$ & $<0.001$ \\
Minimum temperature $\left({ }^{\circ} \mathrm{C}\right)$ & $24.8 \pm 1.0$ & $26.2 \pm 0.7$ & $<0.001$ \\
Maximum temperature $\left({ }^{\circ} \mathrm{C}\right)$ & $27.3 \pm 0.9$ & $29.8 \pm 1.0$ & $<0.001$ \\
Average humidity $(\%)$ & $74.0 \pm 4.6$ & $77.8 \pm 1.3$ & $<0.001$ \\
Minimum humidity $(\%)$ & $71.7 \pm 5.9$ & $75.6 \pm 2.2$ & 0.006 \\
Maximum humidity $(\%)$ & $75.9 \pm 3.9$ & $79.5 \pm 1.0$ & $<0.001$ \\
\hline
\end{tabular}




\section{Estrus and ovulation detection}

Standing estrus response of the sows was monitored twice a day, at 0700 and $1700 \mathrm{hr}$, from the beginning of the day after weaning onwards using a back-pressure test in the presence of a mature boar. The sows that responded to a standing reflex including arched back, cocked ears, and immobilized legs, were considered in estrus. The onset of standing estrus was defined as the time the sows showed first standing reflex minus $5 \mathrm{hr}$ when the sows exhibited first standing estrus at $1700 \mathrm{hr}$ or minus $7 \mathrm{hr}$ when the sows exhibited first standing estrus at $0700 \mathrm{hr}$.

In sows that showed estrus, the timing of ovulation was assessed using transrectal ultrasonography (HS-2000, Honda Electronics Co., Ltd., Toyohashi, Japan) equipped with 7.5 MHz linear probe transducer at $6 \mathrm{hr}$ intervals. A gloved hand, lubricated with liquid paraffin and holding the transducer, was gently inserted into the rectum. Once the urinary bladder was seen on the screen, the ovaries were located by rotating the probe to the left and the right sides of the sow. Both sides of the ovaries were examined and the diameters of 4-8 biggest follicles in each ovary were measured. Ovulation time was defined as the time when a noticeable reduction in the numbers of follicles was observed minus $3 \mathrm{hr}$ [2]. A follicle with diameter $\geq 15 \mathrm{~mm}$ that remained visible for 5 days was defined as cystic ovary [29]. The sows that showed multiple cysts were excluded from ovulation time analysis.

\section{Statistical analysis}

The data were analyzed using the Statistical Analysis System (SAS version 9.0, SAS Institute Inc., Cary, NC, U.S.A.). In the pilot study, WEI, EOI, WOI, injection-to-estrus interval (IEI), and injection-to-ovulation-interval (IOI) were considered as dependent variables. The treatment groups (control, treatment72, and treatment84) were considered as the main effect. To evaluate the effect of the main effect on dependent variables (WEI, EOI, WOI, IEI, and IOI), one-way analysis of variance (ANOVA) was performed using GLM procedure for each dependent variable. The qualitative data for follicle cyst detection were analyzed using Chi-squared or Fisher's exact tests with FREQ procedure.

In the main study, data including WEI, EOI, WOI, IEI, and IOI, were considered as dependent variables. The independent variables including groups (control and treatment) and seasons (cool and hot) were considered as the main effects. The data were analyzed by using multiple ANOVA. Parity, BCS, BF, LL, and LW were considered as covariates. Univariate analysis was performed to check normality of the variables. Spearman's rank correlation test was performed to analyze the correlation among continuous parameters. The BF of sows was distributed normally. The independent variables that were not distributed normally were categorized as follows: parity number [1 $(n=12), 2$ to $3(n=48),>3(n=17)]$, BCS $[<3(n=27)$ and $\geq 3(n=50)]$, LL (days) $[<20(n=45)$ and $\geq 20(n=32)]$, and LW $(\mathrm{kg})[<67(n=42)$ and $\geq 67(n=35)]$. To investigate the independent variables and the interactions that may influence the dependent variables (WEI, EOI, WOI, IEI, and IOI), the multiple linear regression analysis model was developed by backward selection method and was analyzed using GLM procedure. Bonferroni test was used to adjust the multiple analyses. Non-significant independent variables were excluded to avoid over parameterization. The significant independent variables or the interactions that were left from the selection were obtained to fit the model. The average of the largest follicle diameter during $24 \mathrm{hr}$ after buserelin injection and from $24 \mathrm{hr}$ after buserelin injection to ovulation (pre-ovulatory follicle diameter), was calculated by MEANS procedure. The differences in follicle diameter between groups of sows with different IOI were also analyzed with linear regression using GLM procedure. The percentage of sows that ovulated between seasons was analyzed using chi-squared tests with FREQ procedure. Pearson's correlation was used to determine the relationship between maximum follicular sizes at $24 \mathrm{hr}$ after buserelin injection and preovulatory size and estrus/ovulation time (i.e., IEI, IOI, EOI and WOI) in hot and cool seasons. The reproductive performances were compared between control and treatment groups using GLM procedure of SAS. Additionally, reproductive performances were compared between sows inseminated during hot and cool seasons using GLM procedure of SAS. Least-squares means \pm SEM were obtained from each class of the variables and were compared using least significant differences (LSD) test. For all analyses, the alpha level for the determination of significance was 0.05 .

\section{RESULTS}

\section{Pilot study}

All the sows in control, treatment72, and treatment84 showed estrus after weaning, and WEI was not different among groups $(P=0.63)$ (Table 2). One sow in treatment84 developed multiple cysts and it was excluded from ovulation time analysis. The EOI in control sows $(68.1 \mathrm{hr})$ was longer than that in treatment72 and treatment84 sows $(41.3 \mathrm{and} 43.8 \mathrm{hr}$, respectively, $P<0.01)$. The WOI was not different between treatment 72 and treatment 84 sows (129.9 and $137.8 \mathrm{hr}$, respectively) and both intervals were lower than that in control sows $(162.8 \mathrm{hr}, P<0.001)$. In addition, IEI and IOI were not different between treatment72 and treatment84 (Table 2).

\section{Main study}

All the sows in both control (37/37) and treatment (40/40) groups showed estrus onset at $3.8 \pm 0.1$ days after weaning. The WEI was not affected by GnRH treatment at $72 \mathrm{hr}$ post-weaning (Table 3), but was longer in hot season than in cool season $(P=0.04)$. Two out of 37 control sows ( 1 in hot, 1 in cool season) and 2 out of 40 treatment sows ( 2 in cool season) were excluded from ovulation time analyses, due to multiple cysts. The incidence of sows with multiple cysts did not differ between control and treatment groups or between seasons $(P>0.05)$.

The EOI was not affected by season, but was shorter for sows in the treatment groups than those in the control group (38.3 vs. $64.2 \mathrm{hr}, P<0.001)$. The WOI was not affected by season, but was longer in control sows than in treatment sows $(P<0.001)$ (Table 3 and Fig. 1). Among the treatment sows, the IEI was longer in hot season than in cool season $(19.7 \mathrm{vs} .14 .3 \mathrm{hr}, P<0.001)$. The 
IOI was not affected by season $(P=0.27)$; nevertheless, the percentage of sows that ovulated $44-56 \mathrm{hr}$ after injection was higher in cool season than hot season ( 69 vs. $32 \%, P=0.02$ ), while the percentage of sows that ovulated $56-68$ hr after injection was lower in cool season than in hot season $(6.2$ vs. $36.4 \%, P=0.03)$ (Fig. 2). The follicle diameters after buserelin injection in treatment sows with different IOI are presented in Fig. 3 . At $24 \mathrm{hr}$ after buserelin injection, the treatment sows with IOI of $32-44 \mathrm{hr}$ had a higher follicle diameter than those with IOI of $44-56 \mathrm{hr}$ or $>68 \mathrm{hr}(10.1 \pm 0.8 \mathrm{vs} .8 .1 \pm 0.3$ and $7.8 \pm 0.5 \mathrm{~mm}$, respectively, $P<0.05)$. At 24 $\mathrm{hr}$ after injection, there were no differences in follicle diameter among sows with IOI of 44-56 hr, 56-68 hr, or $>68 \mathrm{hr}(P>0.05)$. Pre-ovulatory follicle diameter was smaller in sows with IOI of 44-56 hr than in sows with IOI of 56-68 hr (8.7 $\pm 0.4 \mathrm{vs} .10 .3 \pm$ $0.6 \mathrm{~mm}, P=0.03)$.

In the treatment group, the relationship between maximum follicular sizes at $24 \mathrm{hr}$ after buserelin injection and preovulatory size and estrus/ovulation time (i.e., IEI, IOI, EOI, and WOI) are presented in Table 4. In hot season, the follicular size at $24 \mathrm{hr}$ after buserelin injection was negatively correlated with WOI, IEI, and IOI (Table 4). In cool season, the follicular size at $24 \mathrm{hr}$ after buserelin injection was negatively correlated with IEI (Table 4).

BCS, BF, LW, and LL affected ovulation time (Table 5 and Fig. 4). BCS influenced EOI $(P<0.05)$. Weaned sows with BCS $<3$ had longer EOI than those with $\mathrm{BCS} \geq 3(P=0.01)$. Backfat thickness at weaning was negatively correlated with IOI (IOI=77.6-1.42 (BF), $P=0.04$, Fig. 4). Litter weight at weaning was associated with ovulation time $(P<0.05)$. Sows weaned with heavy LW (LW $\geq 67 \mathrm{~kg})$ had longer IOI than sows weaned with light LW $(\mathrm{LW}<67 \mathrm{~kg})(P=0.02)$. Litter weight $\mathrm{x}$ season interaction affected EOI and WOI. In hot season, sows weaned with heavy LW $(\geq 67 \mathrm{~kg})$ had longer EOI than sows weaned with light LW $(<67 \mathrm{~kg})$, $(P=0.02)$. Sows weaned with heavy LW in hot season had longer WOI than sows weaned with light LW in hot season $(P=0.009)$ and those weaned with heavy LW in cool season $(P=0.020)$. Lactation length affected both estrus onset and ovulation time. IEI was affected by LL and LL $x$ season interaction. Short lactating sows (LL $<20$ days) had longer IEI than long lactating sows (LL $\geq 20$ days) $(P=0.04)$. In hot season, short lactating sows had longer IEI than long lactating sows $(P=0.03)$. Short lactating sows in hot season had longer IEI than sows weaned in cool season, with either short or long LL $(P=0.002)$. In addition, sows with short LL had longer IOI than sows with long $L L \geq 20$ days $(P=0.01)$.

Table 2. Effect of different induction timing on the onset of estrus and ovulation time in the pilot study (least-squares means \pm SEM)

\begin{tabular}{lccc}
\hline \multirow{2}{*}{ Variables } & \multirow{2}{*}{ Control } & \multicolumn{2}{c}{ Treatment } \\
\cline { 3 - 4 } & & $72 \mathrm{hr}$ & $84 \mathrm{hr}$ \\
\hline Number of sows & 8 & 8 & 8 \\
WEI (days) & $3.9 \pm 0.2$ & $3.7 \pm 0.1$ & $3.8 \pm 0.1$ \\
EOI (hr) & $68.1 \pm 5.9^{\text {a) }}$ & $41.3 \pm 3.7^{\mathrm{b})}$ & $43.8 \pm 5.9^{\mathrm{b}}$ \\
WOI (hr) & $162.8 \pm 4.5^{\mathrm{a})}$ & $\left.129.9 \pm 4.5^{\mathrm{b}}\right)$ & $137.8 \pm 2.8^{\mathrm{b}}$ \\
IEI (hr) & - & $16.8 \pm 1.4$ & $9.8 \pm 3.9$ \\
IOI (hr) & - & $58.1 \pm 4.5$ & $54.4 \pm 2.8$ \\
\hline
\end{tabular}

WEI, Weaning-to-estrus interval; EOI, Estrus-to-ovulation interval; WOI, Weaning-to-ovulation interval; IEI, Injection-toestrus interval; IOI, Injection-to-ovulation interval. a, b) Different superscripts within row differ significantly $(P<0.05)$.
Table 3. Effect of groups and seasons on estrus and ovulation times (leastsquares means $\pm \mathrm{SEM}$ )

\begin{tabular}{lccccc}
\hline \multirow{2}{*}{ Variables } & \multicolumn{2}{c}{ Group } & & \multicolumn{2}{c}{ Season } \\
\cline { 2 - 3 } \cline { 5 - 6 } & Control & Treatment & & Hot & Cool \\
\hline Number of sows & 37 & 40 & & 43 & 34 \\
WEI (days) & $3.9 \pm 0.1$ & $3.7 \pm 0.03$ & & $\left.3.9 \pm 0.1^{\mathrm{x}}\right)$ & $\left.3.6 \pm 0.1^{\mathrm{y}}\right)$ \\
EOI (hr) & $\left.64.2 \pm 3.6^{\mathrm{a}}\right)$ & $\left.38.3 \pm 2.1^{\mathrm{b}}\right)$ & & $49.3 \pm 3.2$ & $52.8 \pm 4.1$ \\
WOI (hr) & $\left.157.2 \pm 4.2^{\mathrm{a}}\right)$ & $127.6 \pm 2.0^{\mathrm{b})}$ & & $142.9 \pm 3.4$ & $140.2 \pm 4.9$ \\
IEI (hr) & - & $17.2 \pm 0.8$ & & $19.7 \pm 1.2^{\mathrm{x})}$ & $\left.14.3 \pm 0.5^{\mathrm{y}}\right)$ \\
IOI (hr) & - & $55.7 \pm 2.0$ & & $57.6 \pm 2.3$ & $53.0 \pm 3.6$ \\
\hline
\end{tabular}

WEI, Weaning-to-estrus interval; EOI, Estrus-to-ovulation interval; WOI, Weaningto-ovulation interval; IEI, Injection-to-estrus interval; IOI, Injection-to-ovulation interval. a, b) or $\mathrm{x}, \mathrm{y})$ Different superscripts within row differ significantly $(P<0.05)$; no interaction effects of group and season on estrus and ovulation.

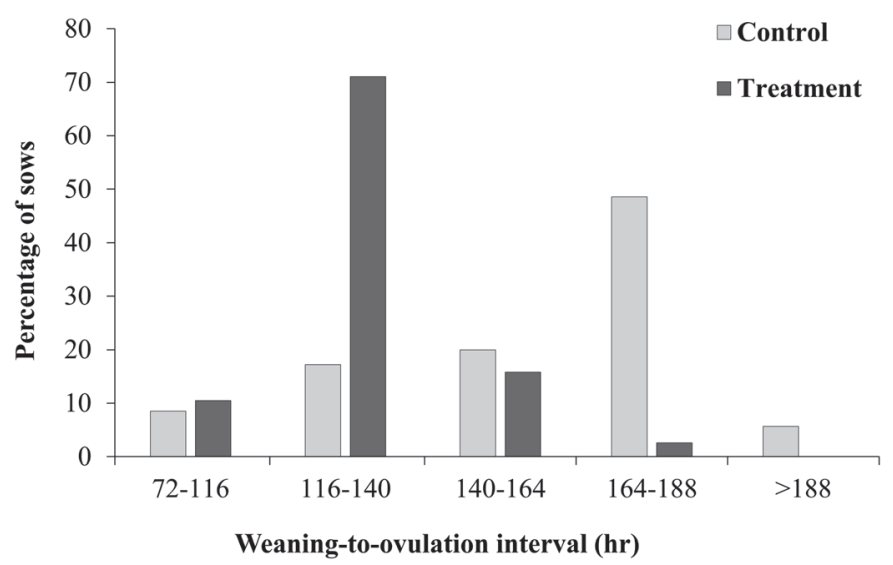

Fig. 1. Distribution of weaning-to-ovulation interval (WOI) in control sows and in sows injected with buserelin at $72 \mathrm{hr}$ post-weaning.

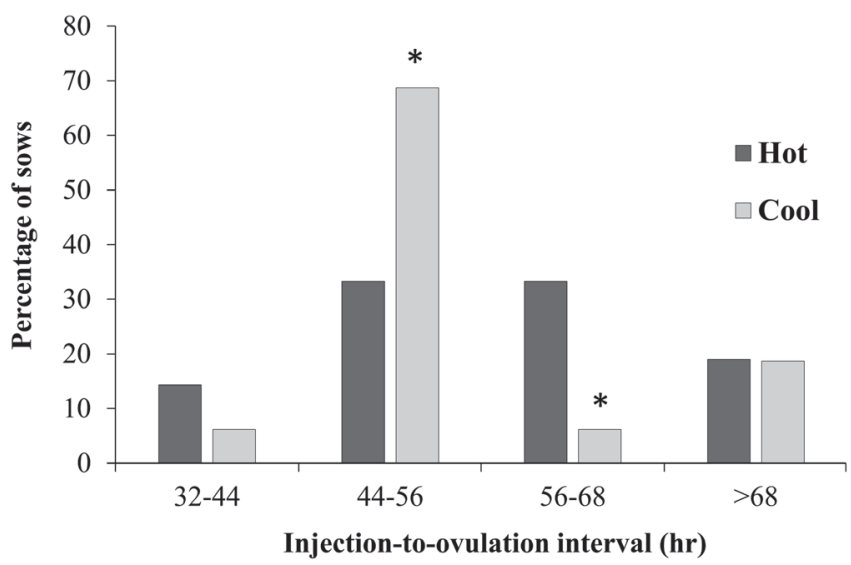

Fig. 2. Distribution of injection-to-ovulation interval (IOI) in treatment sows in hot and cool season. $* P<0.05$. 


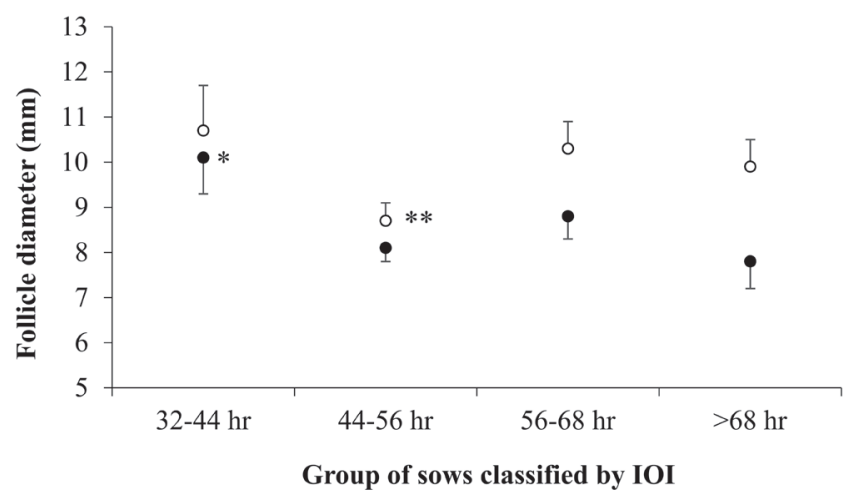

Fig. 3. Maximum follicular size ( $\mathrm{mm})$ at $24 \mathrm{hr}$ after buserelin injection $(\bullet)$ and preovulatory follicular sizes $(\circ)$ in treated sows classified by different injection-to-ovulation intervals (IOI). $* P<0.05$ vs. $\bullet$ in treatment sows with IOI $44-56 \mathrm{hr}$ or $>68 \mathrm{hr}, * * P<0.05 \mathrm{vs}$. $\circ$ in treatment sows with IOI $56-68 \mathrm{hr}$.

Table 4. Relationship between maximum follicular sizes at 24 $\mathrm{hr}$ after buserelin injection, and preovulatory size and estrus/ ovulation time

\begin{tabular}{lccccc}
\hline \multirow{2}{*}{ Follicle size } & \multicolumn{2}{c}{ Hot } & & \multicolumn{2}{c}{ Cool } \\
\cline { 2 - 3 } \cline { 6 - 6 } & At $24 \mathrm{hr}$ & Preovulation & & At $24 \mathrm{hr}$ & Preovulation \\
\hline Number of sows & 22 & 22 & & 16 & 16 \\
Means \pm SD & $8.9 \pm 1.5$ & $9.8 \pm 1.8$ & & $7.9 \pm 1.3$ & $9.3 \pm 2.0$ \\
\hline Pearson's correlation coefficient $(\mathrm{r})$ & & & & \\
EOI (hr) & $-0.060^{\mathrm{NS}}$ & $0.206^{\mathrm{NS}}$ & & $0.154^{\mathrm{NS}}$ & $0.490^{\mathrm{a})}$ \\
WOI (hr) & $-0.363^{\mathrm{b})}$ & $-0.103^{\mathrm{NS}}$ & & $0.050^{\mathrm{NS}}$ & $0.432^{\mathrm{NS}}$ \\
IEI (hr) & $-0.540^{\mathrm{b})}$ & $-0.561^{\mathrm{b}}$ & & $\left.-0.597^{\mathrm{b}}\right)$ & $-0.317^{\mathrm{NS}}$ \\
IOI (hr) & $-0.360^{\mathrm{b})}$ & $-0.106^{\mathrm{NS}}$ & & $0.053^{\mathrm{NS}}$ & $0.435^{\mathrm{NS}}$ \\
\hline
\end{tabular}

EOI, Estrus-to-ovulation interval; WOI, Weaning-to-ovulation interval; IEI, Injection-to-estrus interval; IOI, Injection-to-ovulation interval. a) $P<0.05$, b) $P<0.01$, NS=not significant.

Reproductive performance of sows did not differ significantly between control and treatment groups (Table 6). However, some reproductive traits differed between cool and hot seasons (Table 7). For instance, piglet body weight at birth in sows inseminated during cool seasons was higher than that in sows inseminated during hot season $(P<0.001)$.

\section{DISCUSSION}

The present report incorporates a pilot study that investigated the effects of GnRH agonist, administered at 72 or $84 \mathrm{hr}$ after weaning on estrus and ovulation time, and subsequently investigated the effects of season and other factors on estrus and ovulation time in sows injected with GnRH analogue at $72 \mathrm{hr}$ after weaning. On average, WOI decreased by $30 \mathrm{hr}$ in treated sows compared to control. Moreover, the variation in ovulation timing among individual sows was reduced. For instance, the standard deviation of WOI was reduced from 24.7 to $12.6 \mathrm{hr}$. The proportion of sows that ovulated later than $140 \mathrm{hr}$ after weaning (68 $\mathrm{hr}$ after buserelin injection)

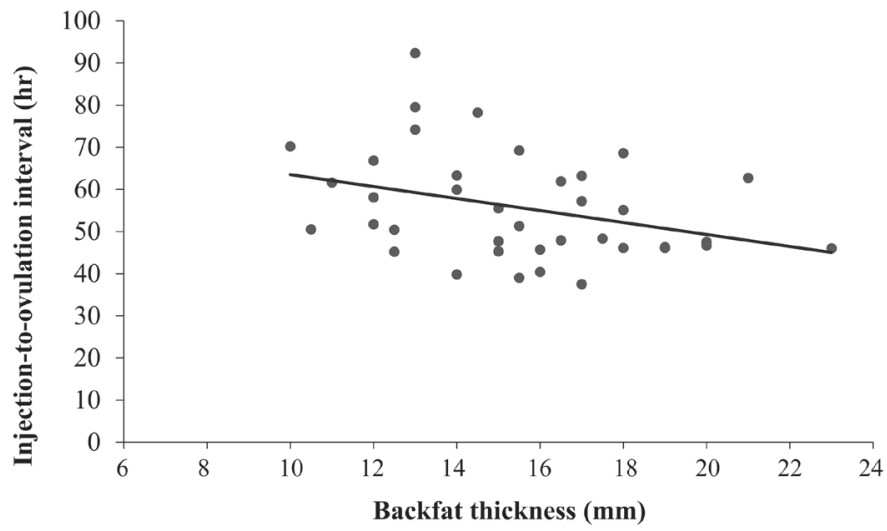

Fig. 4. Relationship between backfat thickness at weaning and injection-to-ovulation interval (IOI) in treatment sows; IOI=77.6-1.42 (BF) $\left(\mathrm{R}^{2}=0.11, P=0.04\right)$.

Table 5. Effect of body condition score (BCS, $n=73)$, backfat thickness $(B F, n=73)$, lactation length ( $L L, n=73)$, and litter weight at weaning $(\mathrm{LW}, \mathrm{n}=73)$ on estrus and ovulation times

\begin{tabular}{|c|c|c|c|c|}
\hline Variables & Covariates & $P$ value & $\begin{array}{c}\text { Classification of } \\
\text { covariates }\end{array}$ & $\begin{array}{l}\text { Least-squares } \\
\text { means } \pm \text { SEM }\end{array}$ \\
\hline \multirow[t]{6}{*}{ EOI (hr) } & BCS & 0.01 & $<3$ & $56.9 \pm 5.0^{\text {a) }}$ \\
\hline & & & $\geq 3$ & $46.4 \pm 2.6^{b)}$ \\
\hline & Season $\mathrm{x}$ LW & 0.03 & Hot, $<67$ & $43.7 \pm 3.2^{\mathrm{A})}$ \\
\hline & & & Hot, $\geq 67$ & $59.9 \pm 4.1^{\mathrm{B})}$ \\
\hline & & & Cool, $<67$ & $54.4 \pm 4.9^{\mathrm{A}, \mathrm{B})}$ \\
\hline & & & Cool, $\geq 67$ & $52.4 \pm 3.9^{\mathrm{A}, \mathrm{B})}$ \\
\hline \multirow[t]{4}{*}{ WOI (hr) } & Season x LW & 0.002 & Hot, $<67$ & $136.4 \pm 3.5^{\text {a) }}$ \\
\hline & & & Hot, $\geq 67$ & $155.3 \pm 4.5^{b)}$ \\
\hline & & & Cool, $<67$ & $\left.146.9 \pm 5.4^{\mathrm{a}, \mathrm{b}}\right)$ \\
\hline & & & Cool, $\geq 67$ & $137.0 \pm 4.3^{\mathrm{a})}$ \\
\hline \multirow[t]{6}{*}{ IEI (hr) } & $\mathrm{LL}$ & 0.03 & $<20$ & $18.6 \pm 1.1^{\text {a) }}$ \\
\hline & & & $\geq 20$ & $14.7 \pm 0.5^{b)}$ \\
\hline & Season $\mathrm{x}$ LL & 0.05 & Hot, $<20$ & $21.3 \pm 1.5^{\mathrm{A})}$ \\
\hline & & & Hot, $\geq 20$ & $15.3 \pm 0.1^{\mathrm{B})}$ \\
\hline & & & Cool, $<20$ & $14.3 \pm 0.6^{\mathrm{B})}$ \\
\hline & & & Cool, $\geq 20$ & $14.2 \pm 0.8^{\mathrm{B})}$ \\
\hline \multirow[t]{5}{*}{ IOI (hr) } & $\mathrm{LL}$ & 0.01 & $<20$ & $59.9 \pm 2.6^{\text {a) }}$ \\
\hline & & & $\geq 20$ & $48.5 \pm 2.0^{b)}$ \\
\hline & LW & 0.02 & $<67$ & $52.5 \pm 2.7^{\mathrm{A})}$ \\
\hline & & & $\geq 67$ & $58.1 \pm 2.9^{\mathrm{B})}$ \\
\hline & $\mathrm{BF}$ & 0.04 & n.c. & - \\
\hline
\end{tabular}

WEI, Weaning-to-estrus interval; EOI, Estrus-to-ovulation interval; WOI, Weaning-to-ovulation interval; IEI, Injection-to-estrus interval; IOI, Injection-to-ovulation interval. a, b) or A, B) Least-square means with different superscripts within each factor differ significantly $(P<0.05)$; Nonsignificant effects are not shown in the table. n.c., not classified due to normal distribution. Group and season were included in WEI, EOI, and WOI analysis, but for IEI and IOI, only season was included. 
Table 6. Reproductive performance of the sows in control and treatment groups (least-squares means \pm SEM)

\begin{tabular}{lccc}
\hline Variable & Control & Treatment & $P$ value \\
\hline Number of sows & 37 & 40 & - \\
Farrowing rate (\%) & 83.3 & 82.5 & 0.923 \\
Total number of piglets born per litter & $12.2 \pm 0.6$ & $11.4 \pm 0.6$ & 0.344 \\
Number of piglets born alive per litter & $11.5 \pm 0.6$ & $10.5 \pm 0.6$ & 0.220 \\
Number of stillborn piglets per litter & $0.34 \pm 0.11$ & $0.36 \pm 0.11$ & 0.862 \\
Number of mummified fetus per litter & $0.37 \pm 0.21$ & $0.61 \pm 0.21$ & 0.452 \\
Piglet body weight at birth (kg) & $1.61 \pm 0.03$ & $1.69 \pm 0.03$ & 0.153 \\
Lactation length (days) & $20.9 \pm 0.4$ & $20.1 \pm 0.4$ & 0.126 \\
Number of piglets weaned per litter & $10.4 \pm 0.12$ & $10.3 \pm 0.13$ & 0.400 \\
Piglet body weight at weaning (kg) & $6.0 \pm 0.02$ & $6.1 \pm 0.03$ & 0.166 \\
\hline
\end{tabular}

Table 7. Reproductive performance of sows inseminated in hot and cool seasons (least-squares mean $\pm \mathrm{SEM}$ )

\begin{tabular}{lccc}
\hline Variable & Hot & Cool & $P$ value \\
\hline Number of sows & 43 & 34 & - \\
Farrowing rate (\%) & 83.3 & 82.3 & 0.910 \\
Total number of piglets born per litter & $11.9 \pm 0.5$ & $11.8 \pm 0.6$ & 0.899 \\
Number of piglets born alive per litter & $10.9 \pm 0.6$ & $11.1 \pm 0.6$ & 0.824 \\
Number of stillborn piglets per litter & $0.34 \pm 0.10$ & $0.36 \pm 0.11$ & 0.926 \\
Number of mummified fetus per litter & $0.64 \pm 0.19$ & $0.33 \pm 0.22$ & 0.312 \\
Piglet body weight at birth (kg) & $1.53 \pm 0.03$ & $1.76 \pm 0.03$ & $<0.001$ \\
Lactation length (days) & $20.9 \pm 0.3$ & $20.0 \pm 0.4$ & 0.074 \\
Number of piglets weaned per litter & $10.8 \pm 0.1$ & $9.9 \pm 0.1$ & $<0.001$ \\
Piglet body weight at weaning $(\mathrm{kg})$ & $6.32 \pm 0.02$ & $5.86 \pm 0.03$ & $<0.001$ \\
\hline
\end{tabular}

reduced from $74.3 \%$ (control) to $18.4 \%$ (treatment). These results are in agreement with a number of previous studies demonstrating that WOI in sows could be shortened by the administration of $50 \mu \mathrm{g}$ buserelin at weaning [35], $10 \mu \mathrm{g}$ at $77 \mathrm{hr}$ after weaning [10], or $10 \mu \mathrm{g}$ at 94 or $104 \mathrm{hr}$ after weaning [22]. This is because, buserelin injection at the optimal time point after weaning could effectively induce LH surge [10]. However, in the present study, the percentage of sows that ovulated within the expected period (i.e., 32-56 hr after GnRH injection) was relatively low (58\%) compared to that in the previous studies [1, 22]. The delayed ovulation response in some of these animals might be related to a number of factors, including parity number of sows, BF, BCS, and season. These factors may influence follicle growth and cause a suboptimal follicle size at the time of hormonal injection in these animals. In the present study, pre-ovulatory follicle size influenced IOI. Small follicles in sows after weaning may need more maturation time to reach the pre-ovulatory follicle size before GnRH administration. This finding indicated that delayed ovulation after buserelin injection could be related to poor follicle growth during lactation, poor follicle quality at weaning (e.g., in sows with poor BCS), or follicles that were too small after weaning. Our findings also indicated that, in hot season, follicular size at 24 hr after buserelin injection was negatively correlated with WOI, IEI, and IOI. This indicated that sows with larger follicular size at $24 \mathrm{hr}$ after buserelin injection had a shorter duration from injection to estrus (IEI) and ovulation (IOI), respectively. In addition, other mechanisms behind poor response to GnRH treatment are discussed below.

In the present study, WEI and IEI were delayed in hot season. This is in agreement with previous studies in either tropical [27] or temperate areas [36]. The seasonal effect on sow reproduction was associated with poor follicle steroidogenesis during the hot season [3]. This, in turn, may be related to a decreased appetite in the hot season that results in increased lactation weight loss [14].

Ovulation induction in weaned sows has been investigated by a number of researchers worldwide during recent years to implement a single fixed-time AI in swine industry [1, 5, 10, 31, 35]. A previous study has recommended performing single fixedtime AI at $32 \mathrm{hr}$ after buserelin injection [10]. Theoretically, the extended fresh semen of boars shows optimal fertility during the first $24 \mathrm{hr}$ after insemination [26]. Therefore, ovulation should take place within $56 \mathrm{hr}(32+24 \mathrm{hr})$ after buserelin injection. In the present study, we presented some novel findings concerning the influence of season on the response of sows to GnRH treatment. For instance, we demonstrated that the percentage of sows that ovulated within $32-56 \mathrm{hr}$ after buserelin injection was higher in $\operatorname{cool}(75 \%)$ than hot $(48 \%)$ seasons. This indicates that high temperature and high humidity during the hot season in Thailand has an effect on GnRH treatment. The reasons could be due to the direct effect of heat stress on the hypothalamus/pituitary function or that hot and/or humid climate compromised follicle growth in post-weaning sows. Lopes et al. [20] found that the follicles of sows reached the pre-ovulatory size later in hot season than in cool season. To date, the effects of season on ovulation time are still controversial $[2,16,33$. However, the study of Belstra et al. [2] suggested that EOI could vary among farms; therefore, 
a study based on only one farm was not enough to represent the effect of season on ovulation time. In addition, Koketsu et al. [18] demonstrated that greater average of daily feed intake in sows during lactation was associated with greater concentrations of insulin and glucose, greater LH pulse frequency prior to weaning, and shorter farrowing-to-estrus interval. Johnston et al. [15] demonstrated that, compared to control environment (mean temperature $20.4^{\circ} \mathrm{C}$ ), hot environment (mean temperature $29.2^{\circ} \mathrm{C}$ ) significantly reduced feed intake of sows ( $6.38 \mathrm{vs} .4 .19 \mathrm{~kg}$ /day) during lactation, reduced weaning weight of sows (193.6 vs. $176.2 \mathrm{~kg}$ ), and reduced the percentage of sows displaying estrus by day 15 post-weaning (93.4 vs. 79.2\%). Likewise, compared to warm season (mean temperature $23.8^{\circ} \mathrm{C}$ ), lactating sows in hot season (mean temperature $26.0^{\circ} \mathrm{C}$ ) had a poorer average daily feed intake ( $-700 \mathrm{~g} /$ day), higher body weight loss (17 vs. $12 \mathrm{~kg})$, and a lower growth rate in their piglets (197 vs. $210 \mathrm{~g} /$ day) [11]. In the present study, although an evaporative cooling system is used, the temperature inside the farrowing house averages $28.0^{\circ} \mathrm{C}$ in hot season, which is $1.8^{\circ} \mathrm{C}$ higher than that in cool season $\left(26.2^{\circ} \mathrm{C}\right)$. The high temperature during the hot season may reduce feed intake of sows and increase the proportion of sows with excessive backfat loss during lactation, and subsequently may cause a poor LH pulse frequency and low insulin and glucose concentrations at weaning. Therefore, follicular growth after weaning in these sows might be compromised. Recently, Costermans et al. [8] demonstrated that a higher weight loss during lactation was also related to a lower percentage of healthy cumulus-oocyte complex. These findings indicate that season or climatic factors may influence feed intake and body weight loss of sows during lactation, and thus, has a significant impact on the response of sows to GnRH treatment.

In the current study, sow conditions, LL and LW affected estrus and ovulation characteristics. In addition, season indirectly affected EOI and WOI by its relationship with LW. After weaning, the BCS of sows has been reported to be associated with follicle size and affected ovulation time [4]. Sows with poor BCS at weaning had smaller follicles and longer WOI compared to sows with BCS of more than 2 [4]. Backfat is an essential source of estrus cycle-related hormones, such as insulin-like growth factor-1 (IGF-1) [24] and leptin [9], which is necessary for the production of reproductive hormone that is associated with granulosa cell proliferation and oocyte development [23, 25]. Moreover, in the present study, we found that sows that were not responding to GnRH treatment (IOI $>68 \mathrm{hr}$ ) had lower BF than those that ovulated before $68 \mathrm{hr}(13.8 \mathrm{~mm}$ vs. 14.9-16.4 mm). Thus, it can be inferred that sows weaned with thick BF are able to respond to ovulation induction better than thin BF sows. In addition, sows nursing a large litter, or those that lost more body protein during lactation had smaller follicles at weaning [7]. Clowes et al. [7] demonstrated that sows that mobilize too much body protein during lactation have a decreased litter growth and ovarian function. Ovarian follicular development was also the most advanced in sows that lost the least protein, and these sows had the heaviest uterine weight and highest estradiol concentration in the follicular fluid [7]. After weaning, small follicles $(<6 \mathrm{~mm})$ have lower levels of LH receptor mRNA expression than larger follicles $(6 \mathrm{~mm})$ [19]. In addition, the level or pulse frequency of LH was lower in sows with higher weight loss during lactation [18]. The effect of LL on ovulation time after buserelin injection has not been investigated. However, it was reported that weaned sows with less than 20 days lactation had a longer weaning-to-LH peak than the conventionally weaned sows [34] and longer estrus duration than those lactating $>20$ days [2, 34]. In addition, De Rensis et al. [9] demonstrated that BF loss in sows during lactation was positively associated with weaning-to-estrus intervals and negatively associated with pregnancy rate. Furthermore, plasma leptin concentrations were higher in sows with high BF thickness ( $>24 \mathrm{~mm}$ ) compared to sows with moderate $(16-24 \mathrm{~mm})$ and low BF thickness $(<16 \mathrm{~mm})$. A recent morphological study has confirmed that leptin exists in different compartments of porcine ovary, including the oocyte, granulosa cells, and corpus luteum, which indicated a close relationship between leptin and ovarian function in pig [23]. These findings indicate that the response of sow to GnRH treatment is associated with excessive loss of body weight and BF thickness during lactation.

In conclusion, the use of a $10 \mu \mathrm{g}$ buserelin injection at $72 \mathrm{hr}$ after weaning was able to induce ovulation in weaned sows in a tropical climate. However, the timing of ovulation still varied among sows. Factors significantly influencing the variation of ovulation timing included season, lactation characteristics, and their interaction. Of all the treated sows, 48 and $75 \%$ ovulated within the expected period (i.e., 32-56 hr after injection) in hot and cool seasons, respectively. Sows that were weaned with lactation length of at least 20 days, litter weight less than $67 \mathrm{~kg}$ or BCS of at least 3 , had better responses to buserelin injection. High BF reserve after weaning is important for ovulation induction response by buserelin injection.

ACKNOWLEDGMENTS. Financial support for the present study was provided by Chulalongkorn University (CUGES_62_01_31_01) and MERCK Animal Health. P. Pearodwong is a grantee of the Royal Golden Jubilee (RGJ) Ph.D. Programme, the Thailand Research Fund (PHD/0064/2557) and the 90th Anniversary of Chulalongkorn University Fund (GCUGR-112-5604040D). The authors are grateful to Charoen Pokphand Foods Public Co., Ltd. and their staff for their help with animal management. Special thanks to W. Maytaweesansurn and S. Thong-in for their technical support in ultrasonography examinations.

\section{REFERENCES}

1. Baroncello, E., Bernardi, M. L., Kummer, A. D., Wentz, I. and Bortolozzo, F. P. 2017. Fixed-time post-cervical artificial insemination in weaned sows following buserelin use combined with/without eCG. Reprod. Domest. Anim. 52: 76-82. [Medline] [CrossRef]

2. Belstra, B. A., Flowers, W. L. and See, M. T. 2004. Factors affecting temporal relationships between estrus and ovulation in commercial sow farms. Anim. Reprod. Sci. 84: 377-394. [Medline] [CrossRef]

3. Bertoldo, M. J., Holyoake, P. K., Evans, G. and Grupen, C. G. 2011. Seasonal effects on oocyte developmental competence in sows experiencing pregnancy loss. Anim. Reprod. Sci. 124: 104-111. [Medline] [CrossRef]

4. Bracken, C. J., Lamberson, W. R., Safranski, T. J. and Lucy, M. C. 2003. Factors affecting follicular populations on Day 3 postweaning and interval to ovulation in a commercial sow herd. Theriogenology 60: 11-20. [Medline] [CrossRef] 
5. Brüssow, K. P., Schneider, F., Kanitz, W., Rátky, J., Kauffold, J. and Wähner, M. 2009. Studies on fixed-time ovulation induction in the pig. Soc. Reprod. Fertil. Suppl. 66: 187-195. [Medline]

6. Cassar, G., Kirkwood, R. N., Poljak, Z., Bennett-Steward, K. and Friendship, R. M. 2005. Effect of single or double insemination on fertility of sows bred at an induced estrus and ovulation. J. Swine Health Prod. 13: 254-258.

7. Clowes, E. J., Aherne, F. X., Schaefer, A. L., Foxcroft, G. R. and Baracos, V. E. 2003. Parturition body size and body protein loss during lactation influence performance during lactation and ovarian function at weaning in first-parity sows. J. Anim. Sci. 81: 1517-1528. [Medline] [CrossRef]

8. Costermans, N. G. J., Teerds, K. J., Keijer, J., Knol, E. F., Koopmanschap, R. E., Kemp, B. and Soede, N. M. 2019. Follicular development of sows at weaning in relation to estimated breeding value for within-litter variation in piglet birth weight. Animal 13: 554-563. [Medline] [CrossRef]

9. De Rensis, F., Gherpelli, M., Superchi, P. and Kirkwood, R. N. 2005. Relationships between backfat depth and plasma leptin during lactation and sow reproductive performance after weaning. Anim. Reprod. Sci. 90: 95-100. [Medline] [CrossRef]

10. Driancourt, M. A., Cox, P., Rubion, S., Harnois-Milon, G., Kemp, B. and Soede, N. M. 2013. Induction of an LH surge and ovulation by buserelin (as Receptal) allows breeding of weaned sows with a single fixed-time insemination. Theriogenology 80: 391-399. [Medline] [CrossRef]

11. Gourdine, J. L., Bidanel, J. P., Noblet, J. and Renaudeau, D. 2006. Effects of breed and season on performance of lactating sows in a tropical humid climate. J. Anim. Sci. 84: 360-369. [Medline] [CrossRef]

12. Gooneratne, A. D., Kirkwood, R. N. and Thacker, P. A. 1988. Effects of injection of gonadotropin-releasing hormone on sow fertility. Can. J. Anim. Sci. 69: 123-129. [CrossRef]

13. Gourdine, J. L., Quesnel, H., Bidanel, J. P. and Renaudeau, D. 2006. Effect of season, parity and lactation on reproductive performance of sows in a tropical humid climate. Asian. Austral. J. Anim 19: 1111-1119. [CrossRef]

14. Gourdine, J. L., Renaudeau, D., Noblet, J. and Bidanel, J. P. 2004. Effects of season and parity on performance of lactating sows in a tropical climate. Anim. Sci. 79: 273-282. [CrossRef]

15. Johnston, L. J., Ellis, M., Libal, G. W., Mayrose, V. B. and Weldon, W. C. and NCR-89 Committee on Swine Management. 1999. Effect of room temperature and dietary amino acid concentration on performance of lactating sows. J. Anim. Sci. 77: 1638-1644. [Medline] [CrossRef]

16. Knox, R. V. and Zas, S. L. R. 2001. Factors influencing estrus and ovulation in weaned sows as determined by transrectal ultrasound. J. Anim. Sci. 79: 2957-2963. [Medline] [CrossRef]

17. Knox, R. V. 2015. Recent advancements in the hormonal stimulation of ovulation in swine. Vet. Med. (Auckl.) 6: 309-320. [Medline]

18. Koketsu, Y., Dial, G. D., Pettigrew, J. E., Xue, J., Yang, H. and Lucia, T. 1998. Influence of lactation length and feed intake on reproductive performance and blood concentrations of glucose, insulin and luteinizing hormone in primiparous sows. Anim. Reprod. Sci. 52: 153-163. [Medline] [CrossRef]

19. Liu, J., Koenigsfeld, A. T., Cantley, T. C., Boyd, C. K., Kobayashi, Y. and Lucy, M. C. 2000. Growth and the initiation of steroidogenesis in porcine follicles are associated with unique patterns of gene expression for individual componentsof the ovarian insulin-like growth factor system. Biol. Reprod. 63: 942-952. [Medline] [CrossRef]

20. Lopes, T. P., Sanchez-Osorio, J., Bolarin, A., Martinez, E. A. and Roca, J. 2014. Relevance of ovarian follicular development to the seasonal impairment of fertility in weaned sows. Vet. J. 199: 382-386. [Medline] [CrossRef]

21. Maes, D. G. D., Janssens, G. P. J., Delputte, P., Lammertyn, A. and de Kruif, A. 2004. Back fat measurements in sows from three commercial pig herds: relationship with reproductive efficiency and correlation with visual body condition scores. Livest. Prod. Sci. 91: 57-67. [CrossRef]

22. Martinat-Botté, F., Venturi, E., Guillouet, P., Driancourt, M. A. and Terqui, M. 2010. Induction and synchronization of ovulations of nulliparous and multiparous sows with an injection of gonadotropin-releasing hormone agonist (Receptal). Theriogenology 73: 332-342. [Medline] [CrossRef]

23. Phoophitphong, D., Srisuwatanasagul, S. and Tummaruk, P. 2017. Leptin immunohistochemical staining in the porcine ovary. Anat. Histol. Embryol. 46: 334-341. [Medline] [CrossRef]

24. Roongsitthichai, A., Koonjaenak, S. and Tummaruk, P. 2013. Association among serum insulin-like growth factor-I, backfat thickness, and age at first observed estrus in gilts. Thai J. Vet. Med. 43: 41-48.

25. Silva, J. R. V., Figueiredo, J. R. and van den Hurk, R. 2009. Involvement of growth hormone (GH) and insulin-like growth factor (IGF) system in ovarian folliculogenesis. Theriogenology 71: 1193-1208. [Medline] [CrossRef]

26. Sumransap, P., Tummaruk, P. and Kunavongkrit, A. 2007. Sperm distribution in the reproductive tract of sows after intrauterine insemination. Reprod. Domest. Anim. 42: 113-117. [Medline] [CrossRef]

27. Suriyasomboon, A., Lundeheim, N., Kunavongkrit, A. and Einarsson, S. 2006. Effect of temperature and humidity on reproductive performance of crossbred sows in Thailand. Theriogenology 65: 606-628. [Medline] [CrossRef]

28. Tantasuparuk, W., Dalin, A., Lundeheim, N., Kunavongkrit, A. and Einarsson, S. 2001. Body weight loss during lactation and its influence on weaning-to-service interval and ovulation rate in Landrace and Yorkshire sows in the tropical environment of Thailand. Anim. Reprod. Sci. 65: 273-281. [Medline] [CrossRef]

29. Tummaruk, P. and Kesdangsakonwut, S. 2012. Factors affecting the incidence of cystic ovaries in replacement gilts. Comp. Clin. Pathol. 21: 1-7. [CrossRef]

30. Tummaruk, P., Lundeheim, N., Einarsson, S. and Dalin, A. M. 2000. Reproductive performance of purebred Swedish Landrace and Swedish Yorkshire sows: I. Seasonal variation and parity influence. Acta Agric. Scand. Anim. Sci. 50: 205-216.

31. Ulguim, R. R., Fontana, D. L., Rampi, J. Z., Bernardi, M. L., Wentz, I. and Bortolozzo, F. P. 2014. Use of porcine luteinizing hormone at oestrous onset in a protocol for fixed-time artificial insemination in gilts. Reprod. Domest. Anim. 49: 756-760. [Medline] [CrossRef]

32. Vesseur, P. C., Kemp, B. and Denhartog, L. A. 1994. Factors affecting the weaning-to-estrus interval in the sow. J. Anim. Physiol. Anim. Nutr. (Berl.) 72: 225-233. [CrossRef]

33. Weitze, K. F., Wagnerrietschel, H., Waberski, D., Richter, L. and Krieter, J. 1994. The onset of heat after weaning, heat duration, and ovulation as major factors in ai timing in sows. Reprod. Domest. Anim. 29: 433-443. [CrossRef]

34. Willis, H. J., Zak, L. J. and Foxcroft, G. R. 2003. Duration of lactation, endocrine and metabolic state, and fertility of primiparous sows. J. Anim. Sci. 81: 2088-2102. [Medline] [CrossRef]

35. Wongkaweewit, K., Prommachart, P., Raksasub, R., Buranaamnuay, K., Techakumphu, M., De Rensis, F. and Tummaruk, P. 2012. Effect of the administration of GnRH or hCG on time of ovulation and the onset of estrus-to-ovulation interval in sows in Thailand. Trop. Anim. Health Prod. 44: 467-470. [Medline] [CrossRef]

36. Yoder, C. L., Schwab, C. R., Fix, J. S., Duttlinger, V. M. and Baas, T. J. 2012. Lactation feed intake in purebred and F1 sows and its relationship with reproductive performance. Livest. Sci. 150: 187-199. [CrossRef] 